\title{
Clinically relevant medicine label-based exercises: a friendly bridge between medicinal chemistry and pharmacotherapeutics
}

\section{Giorgi, Giorgio ${ }^{a}$ and Bravo-Llatas, Carmen ${ }^{b}$}

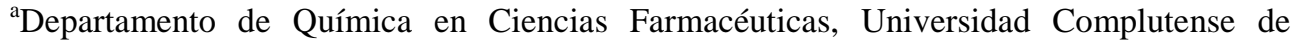
Madrid, Spain, ${ }^{\text {b }}$ rea de Gobierno de Tecnologías de la Información y de Apoyo Técnico al Usuario - Apoyo a Investigación, Universidad Complutense de Madrid, Spain.

\begin{abstract}
Aims. To make the students of Medicinal Chemistry (MC) course for doctor of pharmacy (PharmD) understand how strongly connected the chemical properties of drugs are to their clinical profiles and therapeutics, and determine students' satisfaction degree.

Design. Students in the spring 2013 section of the MC course were taught in a traditional teacher-centered manner. Students in the spring 2015 and 2016 ones had additional guided clinically relevant medicine label-based exercises. They worked in structured self-selected teams and chemically explained the clinical aspects of the selected drugs during oral communication sessions. They were given a 1 to 4 Likert-type scale satisfaction questionnaire, the data were collected and statistically treated.

Results. The project was useful to show the connection between the chemical aspects of drugs and their clinical profiles (mean=3.33 \pm 0.65 ) and globally satisfactory (mean=3.07 \pm 0.47 ). The additional didactic material helped the students in the spring 2016 make the most of the MC course (mean=3.38 $\pm 0.74, p=0.002$ ).
\end{abstract}

Conclusions. Medicine label-based exercises seem to be helpful to understand the connection between medicinal chemistry and pharmacotherapeutics. Feedback from students is generally quite favourable. The approach taken will continue to be modified and expanded.

Keywords: medicinal chemistry; clinical relevance; medicine label-based exercises; team-based learning. 


\section{Introduction}

Medicinal chemistry is a subject that studies the design, synthesis and analysis of drugs: Avendaño (2001). This subject offers pharmacy students the foundational concepts of drug design, drug mechanism of action, structure-activity relationships, acidbase/physicochemical properties, and absortion, distribution, metabolism, excretion and toxicity profiles: Khan et al. (2011). Faculty members teaching medicinal chemistry have sometimes struggled to demonstrate the importance of the discipline to students who will practice pharmacy, as some students struggle to find its relevance and connection to the clinical drug profile, while having their own negative beliefs toward the study of chemistry: Currie et al. (1994). The challenge continues and a historical literature that describes the major efforts by medicinal chemistry faculty members to introduce clinical relevance to the study of the medicinal chemistry is reported: Alsharif et al. (2006) (Table 1).

Table 1. Historical literature describing integration of clinical relevance into Medicinal Chemistry Courses.

Timetable

1985

1990-2006

1994-1998

$1997-2001$

1994-2006

2003

2008

2010

2014

\section{Contribution}

Article by Roche utilizing chemical knowledge in rational therapeutic decision making

Several articles published highlighting different strategies to introduce clinical relevance in the teaching of medicinal chemistry

Patient related case studies in medicinal chemistry and Case Study Textbook in Medicinal Chemistry published

Structurally Based Therapeutic Evaluation concept was introduced as a way to bring relevance, practical applications, interdisciplinary teaching and meeting specific ability based outcomes for pharmacy students in medicinal chemistry

Computerized tutorial in medicinal chemistry

Foye textbook introduces case studies at the end of each chapter Evaluation of an Instructional Model to teach Clinically Relevant Medicinal Chemistry in a Campus and a Distance Pathway: Alsharif et al. (2008)

A Process-Oriented Guided Inquiry Approach to Teaching Medicinal Chemistry: Brown (2010)

Laboratory Exercises to Teach Clinically Relevant Chemistry of Antibiotics:

El Sayed and Chelette (2014) 
Students of Medicinal Chemistry I course, part of the sixth semester within the PharmD curriculum, are taught in a traditional teacher-centered manner, with the majority of class time spent on lectures, seminars, tutorials and laboratory activities. They have the opportunity of synthesizing and analysing drugs in the laboratory, however, there are no designed activities to make the students appreciate how clinically relevant the concepts they study during the medicinal chemistry course are.

\section{Objectives}

The objectives are:

-To introduce students to how knowing the chemical properties of a drug can help understand its kinetics, mechanism of action, place in therapeutic decision making and potential adverse effects on the biological system.

-To prepare additional guided medicine label-based exercises.

-To integrate team-based activities.

-To determine the outcomes.

\section{Design and development}

Students in the spring 2013 Medicinal Chemistry course section were taught in a traditional teacher-centered fashion, however, students in the spring 2015 and 2016 were involved in this project. Participation in the project was optional. This project is composed of three parts:

- The selection and preparation of the additional didactic clinically relevant medicine labelbased material.

- The students' team-based work.

- The preparation of the students' feedback questionnaire, the data collection and their statistic treatment.

\subsection{Selection and preparation of the didactic material}

First of all, the medicine labels were chosen between the most widely dispensed drugs in Spain and included in the subject contents. Afterwards, guided medicine label-based exercises were prepared and uploaded to the blackboard before the semester began. They comprised 15 enzymatic inhibitor drugs ( $7 \beta$-lactam antibiotics and 8 inhibitors of human enzymatic systems) and 4 drugs that interacted with pumps and ionic channels. The 
exercises consisted of questions about chemically focused explanations about the pharmacokinetics and pharmacodynamics profile of the selected drug, the pharmacophore, the structure-activity relationship and the verification of the Lipinsky rule for oral forms. The chemical synthesis and IUPAC name were also asked to be proposed. Spring 2016 students had more exercises available on the blackboard, as the spring 2015 Q6 questionnaire data were analysed before the following academic year began.

\subsection{Students' team-based work}

During the first day of class, the students were briefly introduced to the team-based work, explaining the different roles the students would be playing in their self-selected groups, the goal of the project and how to use the didactic material. Each group was comprised of 3-4 students (one student was the recorder), did the exercises and prepared an oral report. The students worked on the didactic material, prepared their oral presentations and all the experiences were shared at the University during the corresponding 2 hour sessions (3 for the spring 2015 and 5 for the spring 2016 students). Spring 2016 students had more sessions, as the spring 2015 Q6 questionnaire data were analysed to make some improvements before the following academic year began.

\subsection{Students' feedback questionnaire, data collection and statistic treatment}

An anonymous 1 to 4 Likert-type scale questionnaire was contructed to invite students' feedback. Students were asked about their global satisfaction regarding the project (Q1), if participating in the project was useful for them to better understand the relationship between the chemical properties of drugs and the clinical profile (Q2), if they received complete information about the development (Q3) and the goal of the project (Q4), if they would make the most of the Medicinal Chemistry course because of participating in this project (Q5). The survey also included a question in order to obtain an open answer in which students could freely express their comments and suggestions about the project (Q6) (Figure 1). The data were collected at the end of the last session. Data were described by using percentages and means. Non-parametric Mann-Whitney and exact Fisher test were used to analyse the differences between spring 2015 and spring 2016 data distributions. Resampling Bootstrap method with 1000 random samples was applied to analyse the mean differences. Wilcoxon signed-rank test was applied to analyse differences between related data distributions (answers to Q1, Q2 and Q5) and related mean differences (data coming from Q1, Q2 and Q5) were analysed by the resampling 1000 random sample Bootstrap method. In both cases, Bonferroni p-values correction was applied, multiplying p-values by the number of paired comparisons (3). Considered statistical significance level was 0.05. SPSS 22 was the software used. 


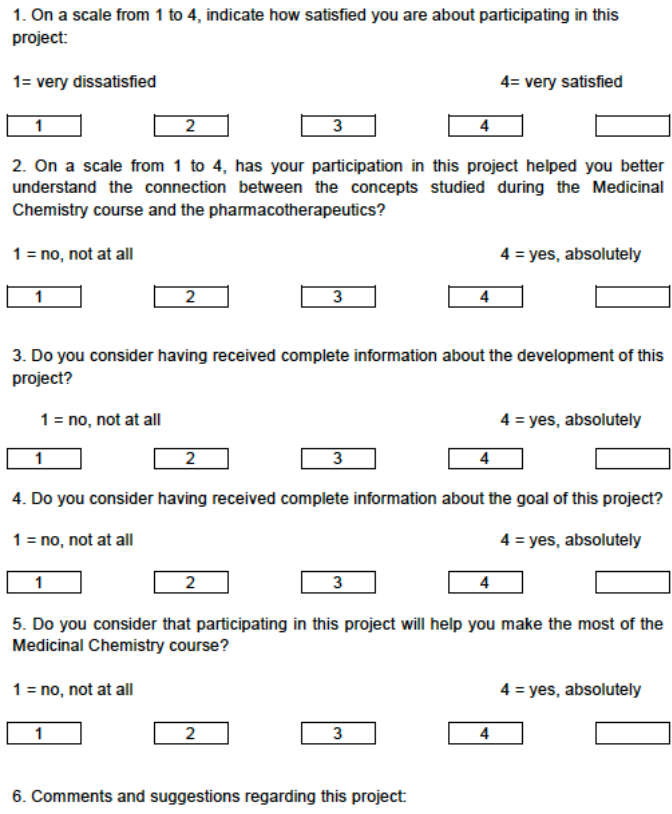

Figure 1. Questionnaire.

\section{Results and discussion}

Students in the spring $2015(\mathrm{n}=34)$ and in the spring $2016(\mathrm{n}=8)$ participated. Results will be globally presented for both groups $(n=42)$, separately when statistically significant differences were found. $78 \%$ were satisfied and $14.6 \%$ very satisfied with the project. Only 9.5\% stated the project was not useful to understand the connection between the contents of the subject and the clinical drug profiles, however $47.6 \%$ stated it was useful and $42.9 \%$ very useful (Figure 2).

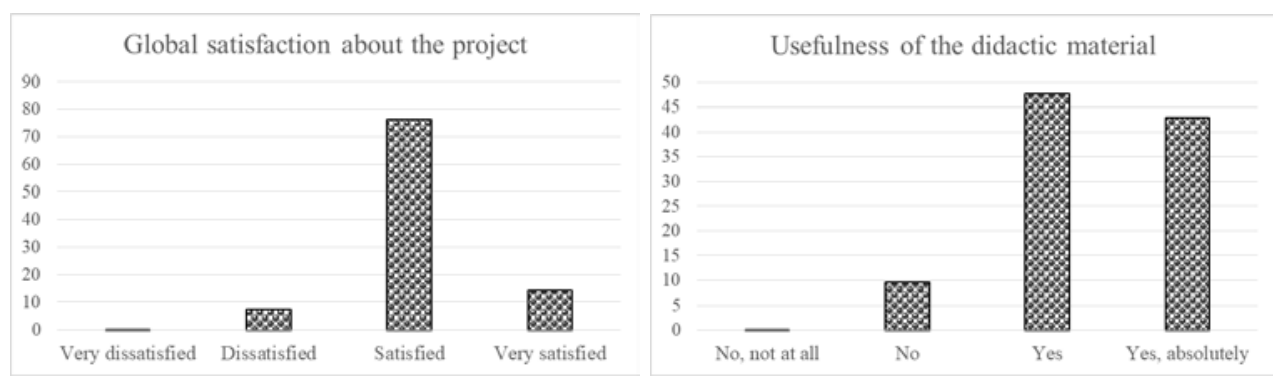

Figure 2. Distribution (\%) for Q1 and Q2. 
47.6\% considered having received complete information regarding the development and the goal of the project. $26.2 \%$ and $35.7 \%$ considered having received complete information regarding the development and the goal of the project in a very high degree of agreement (Figure 3).

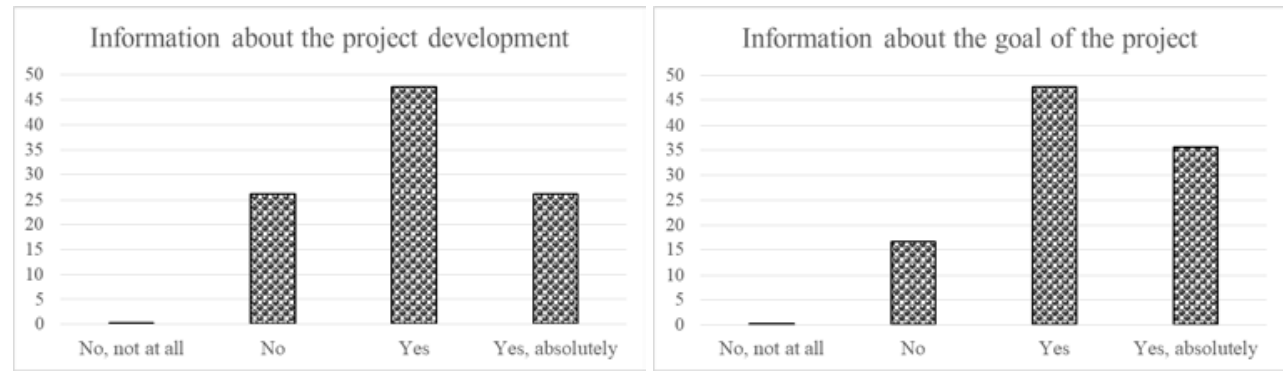

Figure 3. Distribution (\%) for Q3 and Q4.

$42.9 \%$ (11.9\% in a very poor degree) stated that participating in the project would not be helpful to make the most of the Medicinal Chemistry course, however $57.1 \%$ (14.3\% in a very high degree) stated it was (Figure 4).

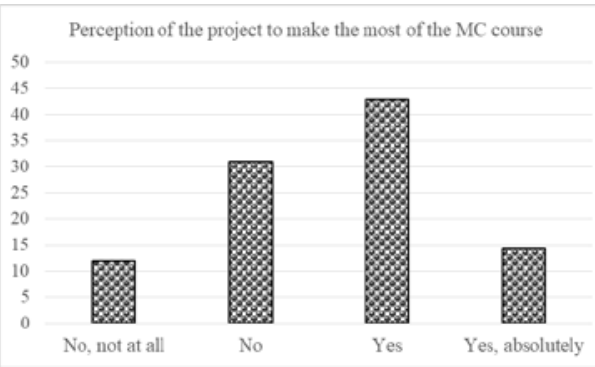

Figure 4. Distribution (\%) for Q5.

The means ( \pm the standard deviation) corresponding to each question of the questionnaire are reported in table 2 .

Table 2. Means ( \pm standard deviation) corresponding to each question of the questionnaire.

\begin{tabular}{cccccc}
\hline Questions & Q1 & Q2 & Q3 & Q4 & Q5 \\
\hline Mean \pm sd & $3.07 \pm 0.47$ & $3.33 \pm 0.65$ & $3.00 \pm 0.73$ & $3.19 \pm 0.71$ & $2.60 \pm 0.88$
\end{tabular}

Spring 2015 students' Q6 data analysis showed that students were generally satisfied with the project but a longer session time or more team-based oral presentation sessions were asked to be considered. They also suggested that the oral communication sessions were more dynamic. Thanks to these suggestions, some design and development changes were 
carried out for the spring 2016 MC course. Spring 2016 students had more medicine labelbased exercises, more sessions to put in common the team-based work and more active participation was required to dynamise the session. These changes led to a statistically significant Q5 related difference between the two groups (spring 2015 and 2016 students). The difference in mean (2.41 \pm 0.82 for spring 2015 students and 3.38 \pm 0.74 for spring 2016 students) $(\mathrm{p}=0.002)$ and in the value distribution were statistically significant (MannWhitney, $\mathrm{p}=0.008$; Fisher, $\mathrm{p}=0.022$ ). 50\% of spring 2015 students stated that participating in the project would not be helpful to make the most of the Medicinal Chemistry course contents. Only $5.9 \%$ of them stated that the participation in the project would be very important to make the most of the Medicinal Chemistry course, while 50\% of spring 2016 students did (Figure 5).

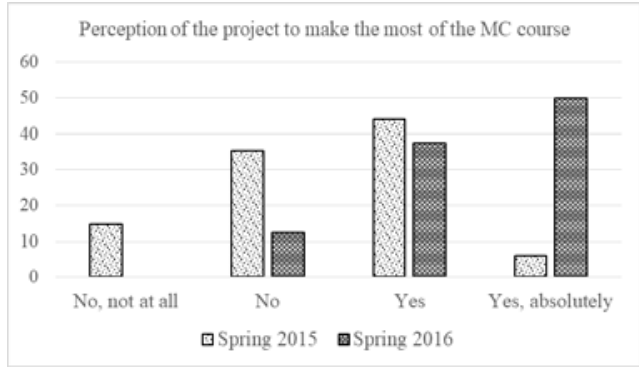

Figure 5. Difference in distribution (\%) for Q5.

Value distribution and mean about the usefulness of the project (Q2) were higher than those regarding the global satisfaction about the project (Q1) (Wilcoxon, $\mathrm{p}=0.015$; Bootstrap, $\mathrm{p}=0.012$ ). $34.1 \%$ gave higher values to $\mathrm{Q} 2$ than to $\mathrm{Q} 1$, only $9.5 \%$ did the opposite. $52.4 \%$ gave higher values about the usefulness of the project (Q2) than about the help of the project to make the most of the MC course (Q5) (only 7.1\% did the opposite) and 39.5\% gave higher values about the global satisfaction (Q1) rather than about the help of the project to make the most of the MC course (Q5) (only 11.9\% did the opposite). Moreover, $23.8 \%$ and $11.9 \%$ of students gave a 2 or 3 unit higher answer, respectively. Q5 value distribution and mean (2.6 \pm 0.89$)$ were lower than those of Q2 (3.33 \pm 0.65$)$ (Wilcoxon, $\mathrm{p}<0.001$; Bootstrap, $\mathrm{p}=0.003$ ) and $\mathrm{Q} 1$ (3.07 \pm 0.47$)$ (Wilcoxon, $\mathrm{p}=0.015$; Bootstrap, $\mathrm{p}=0.015$ ). Statistical differences shown in this paragraph are due to spring 2015 students' data.

\section{Conclusions}

Medicine label-based exercises showed to be a well accepted and powerful tool to make the PharmD students understand the connection between the drug physicochemical properties and their clinical profile. This additional new didactic material seems to be a friendly bridge 
between Medicinal Chemistry and pharmacotherapeutics. The spring 2015 and 2016 students' feedback was quite favourable about the usefulness of the project to connect the concepts studied during the medicinal chemistry course and the clinical drug profile. $78 \%$ of students were globally satisfied and $14.6 \%$ very satisfied about the project. $50 \%$ of spring 2015 students stated that participating in the project would not be helpful to make the most of the Medicinal Chemistry course contents. After carring out the spring 2015 students' suggestions to improve the project, a statistically significant difference was observed between spring 2015 and 2016 students. 87.5\% of spring 2016 students considered that the participation in the project would be helpful (37.5\%) and very helpful (50\%) to make the most of the Medicinal Chemistry course.

\section{References}

Alsharif, N.Z., Galt, K.A., Mehanna, A., Chapman, R., Ogunbadeniyi, A.M. (2006). Intructional Model to Teach Clinically Relevant Medicinal Chemistry. Am. J. Pharm. Educ., 70(4), article 91.

Alsharif, N.Z., Galt, K.A. (2008). Evaluation of an Intructional Model to Teach Clinically Relevant Medicinal Chemistry in a Campus and a Distance Pathway. Am. J. Pharm. Educ., 72(2), article 31.

Avendaño, M.C. (2001). Introducción a la Química Farmacéutica. Madrid: S.A. McGrawHill/Interamericana de España.

Brown, S.D. (2010). A Process-Oriented Guided Inquiry Approach to Teaching Medicinal Chemistry. Am. J. Pharm. Educ., 74(7), article 121.

Currie, B.L., Chapman, R.L., Christoff, J.J., Sikorski, L. (1994). Patient related case studies in medicinal chemistry. Am. J. Pharm. Educ., 58, 446-450.

El Sayed, K.A., Chelette, C.T. (2014). Laboratory Exercises to Teach Clinically Relevant Chemistry of Antibiotics. Am. J. Pharm. Educ., 78(2), article 37.

Khan, M.O.F., Deimling, M.J., Philip, A. (2011). Medicinal Chemistry and the Pharmacy Curriculum. Am. J. Pharm. Educ., 75(8), article 161. 